\title{
A anatomia e onsino de anatomia no Brasil: a escola boveriana
}

\section{Anatomy and the teaching of anatomy in Brazil: the Boverian school}

\section{Ana Carolina Biscalquini Talamoni}

Psicóloga, Doutorado em Educação para a Ciência/Faculdade de Ciências/Universidade Estadual Paulista Julio de Mesquita Filho (Unesp). Rua Rio Branco, 23-34/32A 17014-901 - Bauru - SP - Brasil

carolinatalamoni@gmail.com

\section{Claudio Bertolli Filho}

Professor, Faculdade de Arquitetura, Artes e Comunicação/Unesp, e do Programa de Pós-graduação em Educação para a Ciência/ Faculdade de Ciências/Unesp.

Av. Engenheiro Luiz Edmundo Carrijo Coube, 14-01 17033-360 - Bauru - SP - Brasil

cbertolli@uol.com.br

Recebido para publicação em junho de 2012.

Aprovado para publicação em julho de 2013.
TALAMONI, Ana Carolina Biscalquini; BERTOLLI FILHO, Claudio. A anatomia e o ensino de anatomia no Brasil: a escola boveriana. História, Ciências, Saúde Manguinhos, Rio de Janeiro, v.21, n.4, out.-dez. 2014, p.1301-1322.

\section{Resumo}

A história da anatomia humana, de sua pesquisa e seu ensino no Brasil é tema pouco explorado academicamente. Observa-se a quase inexistência de uma visão mais abrangente do percurso da anatomia contextualizada pelas contingências nacionais, o que gera insegurança entre os pesquisadores que buscam aprofundar-se nessa temática, majorada pelo fato de que muitos dos dados disponíveis nem sempre se apresentam suficientemente apurados. Este texto visa retraçar o desenvolvimento da disciplina anatômica - de sua pesquisa e seu ensino no contexto paulista e nacional -, em muito sintetizada pela ação da autoproclamada escola boveriana de anatomia, fundada pelo médico italiano Alfonso Bovero, por ocasião da criação da Faculdade de Medicina da Universidade de São Paulo.

Palavras-chave: escola boveriana de anatomia; ensino de anatomia; história da anatomia no Brasil.

\section{Abstract}

There is little scholarly research on the history, teaching and research of human anatomy in Brazil. A broader vision of the progress of anatomy under different circumstances in the country is virtually nonexistent, leaving researchers keen to study the subject insecure. This is compounded by the fact that the data available are not always reliable. This text retraces the development of the discipline of anatomy and its research and education in Brazil in general and São Paulo state in particular, which can largely be reduced to the action of the selfproclaimed Boverian school of anatomy, founded by Italian physician Alfonso Bovero at the same time as the Medical Faculty of the University of São Paulo.

Keywords: Boverian school of anatomy; teaching of anatomy; history of anatomy in Brazil. 
$\mathrm{A}$ história da anatomia humana e do seu ensino no Brasil ainda está por ser feita. Com raríssimas exceções, o que se observa no contexto nacional, além da profusão de citações esparsas, é a existência de um número reduzido de livros-textos, artigos e teses acadêmicas que conferem alguma atenção à perspectiva histórica, assim mesmo como estratégias de introdução ou complementação de suas propostas temáticas centrais, mencionando, à guisa de exemplos, os textos assinados por Erhart (1973), Kruse (2004) e Montes (2009). Em outras iniciativas, a história ganha maior destaque quando o interesse do pesquisador volta-se para o cenário internacional; assim fez Terra (2007), que se apoiou, sobretudo, em dados históricos para avaliar a iconografia anatômica europeia no decorrer da modernidade clássica.

A regra parece ser negar à história da anatomia e do ensino de anatomia no Brasil a posição de objetos privilegiados de inquirições, servindo-se o pesquisador de dados fragmentados como plataforma auxiliar para suas averiguações. Se de inegável importância, a recorrência ao enfoque histórico como instrumento secundário de análise tem como contraponto a não realização de estudos mais aprofundados sobre a trajetória temporal do saber anatômico e seu ensino. Com isso, a inexistência de uma visão mais abrangente do percurso da anatomia contextualizada pelas contingências nacionais tem gerado uma série de inseguranças entre os pesquisadores, até porque muitos dos dados disponíveis e frequentemente invocados nem sempre se apresentam suficientemente apurados.

A partir dessas constatações, define-se o objetivo deste texto: retraçar o desenvolvimento da disciplina anatômica bem como seu ensino no contexto paulista, em muito sintetizada pela ação da autoproclamada "escola boveriana". A limitação do foco ao estado de São Paulo não implica a limitação da abordagem ao território bandeirante, e isso por dois motivos. O primeiro deles deve-se à circunstância de, pela especificidade da proposta, ser necessário ir buscar no contexto europeu as bases da formação intelectual de Alfonso Bovero, o mentor da escola que se estudará; o segundo à necessidade de voltar-se para o contexto nacional mais amplo, já que os representantes da Escola Boveriana também incorporaram um movimento político-acadêmico que, ao tentar tornar hegemônicas as suas concepções de pesquisa e ensino, buscou disseminar-se no âmbito das instituições médico-biológicas de outros estados brasileiros.

A proposta aqui incorporada coloca em tela dois tipos de desafios. Inicialmente, o próprio questionamento sobre a efetiva existência de uma escola boveriana de anatomia. A admissão da existência de uma escola anatômica paulista implica a necessidade de clareamento do que se entende, no plano sociofilosófico, como os elementos definidores de uma escola. Acompanhando e adaptando as propostas de Lalande (1999, p.318) para o objeto focado, assume-se que uma escola de pensamento caracteriza-se pela existência de um grupo de estudiosos que compartilham um conjunto de conhecimentos com um alto grau de harmonia e contam com um chefe ou uma sucessão de chefes admitidos como legítimos pelo grupo. Além disso, uma escola deve contar com uma organização que lhe seja própria e, com um local fixo de reunião, que pode ser um prédio e/ou um espaço simbólico, onde ocorram reuniões periódicas, como congressos científicos, durante as quais sejam (re)lembrados, exaltados e ritualizados os pressupostos básicos, assim como cultuados os pais-fundadores da própria escola. 
O segundo desafio constitui-se nas próprias fontes documentais. Sabe-se que uma parcela significativa das fontes primárias que podem permitir a reconstrução das trajetórias e das atividades desempenhadas pelos primeiros anatomistas congregados na nascente Faculdade de Medicina de São Paulo está depositada no Museu de Anatomia Humana "Alfonso Bovero", do Instituto de Biociências da Universidade de São Paulo (ICB/USP), cujo acervo encontra-se vedado à consulta devido ao fato de estar em fase de reorganização, inviabilizando o trabalho dos pesquisadores. Sendo assim, ressalta-se que este texto não tem como objetivo central a análise de documentos, mas sim a organização de informações esparsas que se encontram disseminadas em um grande número de obras impressas. Em decorrência, este artigo tem como intenção chamar a atenção sobre um tema ainda preterido pela historiografia nacional, na esperança de que ele sirva como uma espécie de introdução que sensibilize os pesquisadores para a elaboração de investigações mais aprofundadas sobre o tema.

\section{Os primórdios do ensino de anatomia}

Os primeiros registros de estudo e de ensino da anatomia remontam à Escola de Alexandria em que, segundo os registros de Galeno, teriam sido realizadas as primeiras dissecações públicas de animais e corpos humanos (Singer, 1996, p.48). No entanto, as dissecações para fins de estudo sempre geraram polêmicas, e pode-se afirmar que foi apenas a partir do século XIV que, na Europa, mais especificamente na Universidade de Bolonha, elas se tornaram parte do ensino médico sob os auspícios de Mondino de Luzzi (1270-1326). Nesse período, por influência do movimento escolástico, os estudos e investigações em anatomia baseavam-se, sobretudo, na tradução de obras e tratados anatômicos, sendo a dissecação um método de averiguação de dados preexistentes.

Foi apenas no século XVI e em pleno movimento renascentista que Andreas Vesalius (1514-1564) publicou a obra De humanis corporis fabrica (1543). As contribuições de Vesalius ao desenvolvimento da ciência anatômica são inúmeras. No campo do ensino, destacou-se sua ardorosa defesa da prática sistemática da dissecação de animais e de seres humanos; no campo da pesquisa, a inovação de sua proposta foi traçar paralelos entre as estruturas corporais humanas e animais, demonstrando as diferenças entre elas, e, portanto, apontando os lapsos da anatomia galênica que predominava nos principais livros-textos utilizados até então, como o Anothomia de Mondino de Luzzi, publicado em 1493 (Mandressi, 2003, p.81).

Outro aspecto importante da obra de Vesalius foi a utilização de figuras que buscavam situar conhecimentos científicos e anatômicos em um contexto natural e social mais amplo, dando de certa forma "vida" aos cadáveres representados e alçando assim a figura do anatomista "carrasco", até então considerado um personagem sombrio ligado à morte, ao patamar de profissional socialmente aceito, sobretudo com o advento das dissecações públicas anuais, que se tornavam cada vez mais comuns no âmbito europeu (Le Breton, 1993, p.192). O desenvolvimento da anatomia descritiva teve na figura e na obra de Vesalius um momento de renovação a partir do qual, paulatinamente, novas estruturas corporais foram sendo identificadas e/ou nomeadas. Dentre seus discípulos destacaram-se Gabriel Falópio (1523-1562) e Fabricio Aquapendente (1537-1619). 
Segundo Coleman (1977, p.17), a anatomia descritiva, ao final do século XVIII, já tinha investigado, identificado e descrito grande parte das estruturas corporais humanas, cedendo lugar, de forma gradual, a outras disciplinas que viriam a estabelecer as relações entre essas estruturas, como a fisiologia. Para o autor, a anatomia descritiva falhou ao mostrar-se "estática", uma vez que não revelava as relações entre as estruturas identificadas, e, certamente, esse pode ser um dos motivos pelos quais, no século XIX, com o surgimento da medicina experimental, a anatomia perde parte de seu campo de atuação para disciplinas como a fisiologia e a anatomia patológica, o que evidenciava um novo posicionamento epistemológico, funcionalista e experimental para os modernos estudos acerca dos condicionantes do estado normal e patológico do corpo humano.

Exemplo disso é o fato de que dentre os nomes proeminentes da anatomia do século XIX destacaram-se William Sharpey (1802-1880) e Henry Gray (1827-1861), ambos reconhecidos por suas contribuições tanto na organização de algumas das edições do Quain's Anatomy ${ }^{1}$ quanto na publicação do Gray's Anatomy, obras destinadas à melhoria do conhecimento da anatomia humana por parte de médicos cirurgiões cujas atividades foram impulsionadas pelo advento da anestesia (Hayes, 2008, p.18).

\section{A anatomia em Portugal e no Brasil nos séculos XVIII e XIX}

No transcorrer do século XVIII, a pesquisa e o ensino de anatomia em Portugal apresentavam-se defasados em relação a outros centros europeus, já que se mostravam, sobretudo, teóricos, instruídos ainda pelos ensinamentos contidos nos textos de Hipócrates, Galeno, Rhazes e Avicena, como ocorreu na Itália do século XIV. Tais iniciativas eram precárias não só por serem raros os especialistas no setor, o que impunha a contratação de anatomistas franceses e italianos pelas escolas médicas lusitanas, mas também porque o governo português, de tempos em tempos, proibia a dissecação de cadáveres humanos para fins de instrução dos alunos de medicina, recorrendo aos corpos de animais para o estudo da anatomia humana.

A tradição aristotélico-tomista herdada da Idade Média tinha como opositores os intelectuais lusitanos classificados como "estrangeirados", isto é, que buscavam renovar o conhecimento a partir do empirismo e do experimentalismo que vigorava na prática e no ensino científico na França e na Inglaterra. Fruto do empenho desse grupo em "modernizar" a cultura portuguesa segundo as propostas da filosofia iluminista, em 1772, com o apoio do rei dom José I, foram aprovados os Estatutos da Universidade de Coimbra, que, no referente à formação e prática da "medicina empírico-racional", buscou estabelecer pontes entre a "arte de curar" e o "ofício do cirurgião", cobrando de todos os médicos conhecimentos aprofundados da anatomia humana, permitindo, aliás, a dissecação de cadáveres, estratégia vista como fundamental para o melhor entendimento das doenças e da realização de cirurgias. Mesmo contando com oposições que entendiam o ensino de anatomia como "inútil e desnecessário", construiu-se um teatro anatômico em substituição às diminutas salas nas quais se dissecavam mais animais do que cadáveres humanos, refletindo uma nova postura de relação entre a teoria e a prática no processo de conhecimento do corpo humano e também do ensino de medicina (Abreu, 2007, p.150). 
Acredita-se que, por causa das reticências de modernização da medicina portuguesa, as academias e hospitais localizados em lugares distantes do olhar metropolitano, mais minucioso, burlavam com certa liberdade a legislação vigente, servindo como possíveis centros de pesquisa e ensino de anatomia. Nos primeiros anos do século XVIII, Luís Gomes Ferreira, um dos lusitanos que se transferiu para o Brasil para atuar como cirurgião da capitania das Minas, "realizou dissecação em um escravo com o intuito de descobrir a causa da morte do cativo" (Abreu, 2007, p.152). Apesar disso, a carioca Academia de Seletos tem sido indicada como o local onde foram realizados os primeiros estudos de anatomia, cabendo a primazia ao cirurgião Maurício da Costa que, em 1752, publicou as primeiras memórias relativas às questões anatômicas. No plano do ensino, exemplar mostra-se a trajetória de João Álvares Carneiro que, emblematizando um novo tempo no ensino de medicina antes de se tornar um dos mais renomados cirurgiões do seu período, em 1790, quando contava com 14 anos de vida, ingressou como aprendiz na Santa Casa do Rio de Janeiro. Lá, foi aluno do cirurgiãomor Antonio José Pinto, a quem se atribui o pioneirismo de lecionar o primeiro curso de anatomia na corte e, provavelmente, em todo o Brasil (Santos Filho, 1977, p.294).

Ainda no final do século XVIII, há notícias de que a anatomia humana era ensinada no Hospital Militar de Vila Rica. A necessidade de assistir os soldados impunha a premência do conhecimento dos segredos internos dos corpos para a proteção da própria Coroa e, por isso, Antonio José Vieira de Carvalho, cirurgião do Regimento de Cavalaria das Minas Gerais foi convocado para ministrar "aulas de anatomia" (Aires Neto, 1948, p.78-79).

A transferência forçada da corte portuguesa para o Brasil, em 1808, ensejou que, em fevereiro daquele ano, fosse criada a escola médica da Bahia. Fundada como Escola de Cirurgia do Hospital Militar, a instituição foi organizada sob a liderança do pernambucano José Ferreira Picanço, o qual fora discípulo do anatomista Manuel Pereira Teixeira, tendo-se especializado posteriormente em métodos de ensino de anatomia na Universidade de Montpellier (Aires Neto, 1948, p.79).

Nessa escola, que mais tarde foi renomeada como Faculdade de Medicina da Bahia, o primeiro lente de anatomia foi o português Soares de Castro que, em 1812, publicou uma série de quatro fascículos sobre osteologia, miologia, angiologia e nevralgia, os quais contavam com descrições anatômicas. Soares de Castro foi sucedido no cargo de professor de anatomia pelo inglês Johannes Abbot; ao longo de trinta anos de docência, Abbot introduziu de vez a prática de dissecação de cadáveres humanos no ensino médico nacional e fundou o primeiro museu anatômico brasileiro (Aires Neto, 1948, p.84).

No mês seguinte à fundação da escola médica baiana, dom João VI criou a escola médica do Hospital Militar do Morro do Castelo, no Rio de Janeiro, indicando para lente de anatomia Joaquim da Rocha Mazarém, que mais tarde traduziu para o português vários textos assinados por Bichat e por Antelmo Richeraud. Alguns anos depois, Mazarém foi substituído por Joaquim José Marques, que ocupou a cátedra de "anatomia teórica e prática" e de "fisiologia, segundo as partes e sistemas da máquina humana" (Aires Neto, 1948, p.85; Santos Filho, 1991, p.44-45).

Com isso, favoreceu-se o ensino sistemático de anatomia como condição para a prática médica em geral e a cirurgia em especial. Nesse âmbito, é preciso notar que as duas escolas médicas brasileiras criadas pela corte portuguesa foram orientadas pela vertente francesa da medicina, que então priorizava o atendimento do paciente "à beira do leito", dando impulso 
a uma formação de médicos destinados ao exercício da clínica e auxiliando também na resolução dos desafios propostos pela saúde pública (Araujo, 1979, p.32). Em âmbito global, a tendência francesa contrapunha-se à abordagem anatomoclínica emblematizada pela medicina germânica, fortemente influenciada pelas pesquisas laboratoriais, e cuja ascendência no Brasil terá como símbolo maior a Faculdade de Medicina de São Paulo, inaugurada na segunda década do século XX.

No Brasil da segunda metade do Oitocentos, os estudos no campo da anatomia mostravamse subordinados a outras áreas, especialmente à patologia e à medicina cirúrgica. Certamente por isso, em 1854, no decorrer dos debates alimentados pela reforma curricular das escolas médicas, advogou-se a supressão do ensino de anatomia patológica dos cursos, proposta criticada pela "ala jovem" dos médicos cariocas (Torres Homem, 1862, p.51).

O próprio Torres Homem buscou introduzir na Gazeta Médica do Rio de Janeiro, periódico do qual era um dos redatores, notícias sobre a carência de equipamentos, materiais e funcionários na cadeira de anatomia da escola médica carioca, além de assinar um artigo no qual o autor se contrapunha a "certos homens, aliás, ilustrados" que criticavam a continuidade das aulas de anatomia, enfatizando a importância do ensino de anatomia geral e patológica para os alunos de medicina (Torres Homem, 1862, p.51-52). Mais do que isso, esse clínico buscou sistematizar os conhecimentos e divulgar a prática da anatomia patológica, elaborando um compêndio no qual apresentava a descrição de necropsias e suas possíveis contribuições para o diagnóstico das doenças (Torres Homem, 1870).

Nesse período, a anatomia, quer a descritiva quer a patológica, só era reconhecida no contexto da formação do médico em termos restritos, isto é, como uma "disciplina ponte", portanto subordinada a outros setores do saber médico. No introito de uma de suas obras, Torres Homem confidenciou estar sendo caluniado por alguns dos seus pares pelo fato de ser favorável à prática da necroscopia, que havia sido regulamentada na França nesse mesmo período. Em seguida, explicou por que se mostrava defensor da realização de autópsias como estratégia para o ensino de medicina:

A quarta parte [do livro] reservei para o estudo das autópsias, debaixo do ponto de vista clínico, isto é, como fonte de instrução em medicina prática. Esforcei-me por dar ao meu livro todo o cunho prático, fugindo, tanto quanto possível, das abstrações teóricas e das discussões especulativas estranhas à clínica, e que nada de útil a ela fornecessem (Torres Homem, 1870, p.IX).

Enfim, não havia, no cenário brasileiro, maiores empreendimentos que visassem à consagração da anatomia enquanto campo disciplinar autônomo, situação que se iria reproduzir no século XX, especialmente entre os especialistas formados no Rio de Janeiro e na Bahia, mesmo após terem surgido outros cursos universitários que faziam uso do conhecimento anatômico.

\section{A trajetória de Alfonso Bovero}

Alfonso Bovero nasceu no Piemonte em 1871 e obteve seu diploma aos 24 anos na escola médica da Universidade de Turim, sob supervisão do anatomista Carlo Giacomini (1837-1898), 
com quem trabalhou por aproximadamente três anos antes de graduar-se. Em seguida, Bovero foi nomeado assistente de Giacomini e, nessa condição, o pupilo empenhou-se em desenvolver trabalhos correlatos aos do seu mentor, que se dedicava ao estudo da morfologia cerebral, antropologia criminal e teratologia, sendo uma de suas contribuições mais significativas, no que tange à prática anatômica, o aperfeiçoamento da técnica de emprego da glicerina para a fixação de peças anatômicas (Lacaz, 1986, p.34-35).

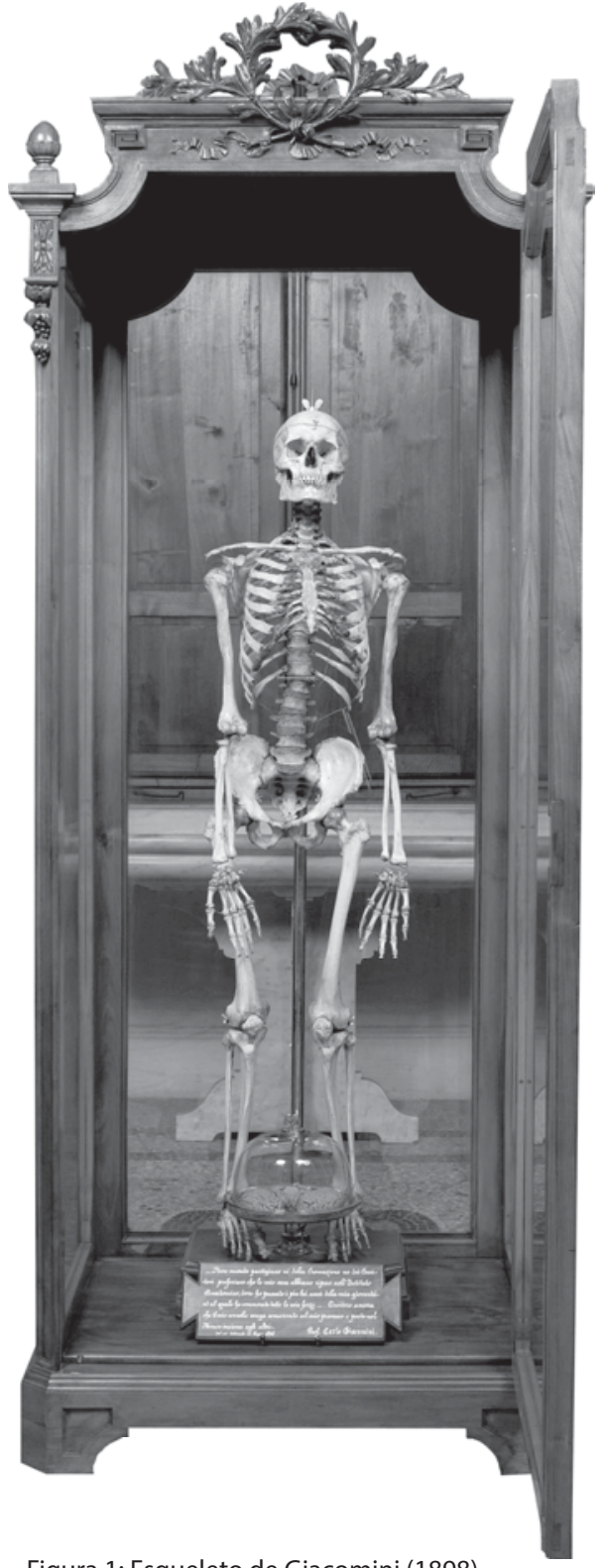

Figura 1: Esqueleto de Giacomini (1898), Museu da Universidade de Turim (Fonte: http://www.museounito.it/anatomia/ visita/fin_foto/partevisibile/pag4/fin_04.html Acesso em: 27 mar. 2011)

Nessa condição, Bovero aproveitou a oportunidade para dedicar-se às pesquisas pautadas por uma forte influência da vertente descritiva e sistêmica da anatomia, aliada à tradição de dissecação, que remonta ao período de Vesalius (15141564). Com o apoio de Giacomini, Bovero viu-se livre para aprimorar seus conhecimentos na Alemanha, onde permaneceu nos anos de 1897 e 1898. Retornou à Itália devido à morte de seu mentor e, nessa ocasião, participou não somente de sua autópsia, como realizou a promessa anteriormente feita, de dissecar seu corpo para estudos.

Na Alemanha, Bovero trabalhou no Anatomishbiologisches Institut, sediado em Berlim, estudando anatomia com Heinrich W. von Waldeyer e histologia e embriologia com Oskar Hertwig (Lacaz, 1989, p.66). Sua opção por prosseguir os estudos na Alemanha deu-se não só porque naquele país se encontravam os principais centros de pesquisa na área, mas também porque lá ressurgia com vigor a anatomia comparada, vertente que contava com raros especialistas na Itália. No plano epistemológico, ao linhagem germânica da anatomia guardava clara influência da teoria darwiniana e visava, sobretudo, ao desenvolvimento de pesquisas instrumentais e experimentais que superavam a clássica vertente descritiva que até então prevalecera nessa disciplina.

Nesse encaminhamento, torna-se importante para o bom entendimento da trajetória intelectual de Bovero inteirar-se, mesmo que em linhas gerais, do novo enquadramento que estava sendo conferido à anatomia em Berlim. Isso porque as novas propostas alemãs seriam incorporadas pelo médico italiano e, anos depois, constituiriam uma das principais marcas das pesquisas e do ensino levado a efeito por Bovero no cenário brasileiro. 


\section{A proposta germânica}

A teoria darwiniana de meados do século XIX confirmara a animalidade do ser humano e, consequentemente, a aplicabilidade dos métodos de indagação da natureza utilizados pela filosofia natural no estudo do homem. As qualidades físicas humanas, assim como as dos animais, passaram a ser objeto de sistemáticas investigações e foram essenciais para o desenvolvimento da antropologia física.

As pesquisas laboratoriais em anatomia, sob a forte influência da fisiologia experimental e dos avanços nas técnicas de mensuração e visualização macro e microscópicas dos organismos vivos favoreceram o surgimento na Alemanha do movimento do "reducionismo fisiológico". Segundo Coleman (1977, p.150-151):

Eles [os cientistas] mantiveram a premissa da existência de movimento na matéria bruta. A noção de força e movimento da matéria bruta constituía-se em fonte satisfatória de explicação. Esta foi uma nova e radical geração, materialista, que, em termos filosóficos, tentou efetuar uma revolução na ontologia ao reavaliar as prioridades, de modo a conferir a influência dos princípios da mecânica nas ciências (tradução livre dos autores).

A vertente mais conservadora do reducionismo alemão foi representada pelas pesquisas desenvolvidas por Johannes Müller e seus alunos - Theodor Schawann, Hermann von Helmholtz, Karl Ludwig, Emil-du-Bois-Reymond, Ernest Brücke, Rudolf Virchow e Karl Reichert. Johannes Peter Müller (1801-1858), fisiologista e anatomista comparado, estudou na Universidade de Bonn e complementou sua formação na Universidade de Berlim, sob supervisão do naturalista Karl Asmund Rudolph (1771-1832), cuja cátedra viria a assumir em 1833. Dentre suas contribuições, destacou-se o aumento da compreensão dos mecanismos da fala e da audição; em citologia, descreveu algumas propriedades físicas da linfa e do sangue e, em anatomia comparada, dedicou-se ao estudo dos peixes e invertebrados marinhos.

Em 1858, o anatomista alemão Karl Reichert (1811-1883), seu discípulo, sucedeu-o na cátedra. Reichert, por sua vez, foi mestre do citologista Heinrich Wilhelm von Waldeyer (18361921), que ficou conhecido, em 1890, por descobrir a divisão do cromossomo. Waldeyer viria a trabalhar temporariamente com Bovero na Universidade de Berlim.

Müller também foi mestre do médico e patologista alemão Rudolf Virchow (1821-1902), considerado precursor da citologia moderna por ter ampliado a teoria celular em seu texto Omnis cellula e cellula, datado de 1855. Em 1856, assumiu a cátedra de anatomia patológica da Universidade de Berlim.

No que tange à morfologia, o impacto da teoria darwiniana também foi significativo. Seus progressos deram-se em dois setores. A morfologia comparada, que privilegiou a investigação da realidade biológica do ponto de vista morfológico, e a evolucionista, vertente que prevaleceu na Alemanha e debruçou-se sobre a gênese evolutiva das espécies (Coleman, 1977, p.87-88). Esta última questionava se a anatomia comparada, assim como qualquer disciplina descritiva, poderia, por si só, respaldar as múltiplas variantes implicadas no processo evolutivo dos animais, e sobretudo do homem (Laín Entralgo, 1999).

A aparente oposição entre essas duas vertentes nunca foi levada a cabo, graças ao valor da morfologia, cuja importância foi logo reconhecida para o entendimento da evolução das 
espécies, inclusive da humana. Ressaltam-se aqui as contribuições de Thomas Henry Huxley (1825-1895), de Richard Owen (1804-1892) e dos morfologistas evolucionistas como Francis Maitland Baupour (1851-1882) e Ernst Heinrich Haeckel (1834-1919).

Haeckel, que fora aluno de Virchow na Universidade de Berlim, publicou em 1866 a obra Generelle Morphologie der Organismen, na qual expôs a hipótese da associação entre ontologia e filogenia. Graças a sua obra, afloraram as primeiras discussões sobre os determinantes biológicos, sociais e filogenéticos na constituição do organismo humano, ou seja, da genealogia humana. Haeckel foi professor do embriologista Oscar Hertwig (1849-1922), na Universidade de Jena. Hertwig, em 1899, ocupou a cátedra de anatomia da Faculdade de Medicina da Universidade de Berlim, onde trabalhou com Bovero.

O retorno de Bovero à Itália permitiu sua nomeação como settore capo, isto é, dissecador chefe da Escola de Medicina de Turim, sendo que, em 1901, galgou também o posto de catedrático de anatomia, fisiologia e higiene aplicadas à educação física na Escola Real Feminina de Ginástica de Turim. Em 1902, recebeu o título de livre-docente de anatomia e, três anos depois, passou a ocupar a cátedra de anatomia da Universidade de Gagliari, na Sardenha, ao mesmo tempo que atuou, em regime de substituição, na cátedra da mesma disciplina na Universidade de Turim (Montes, 2009, p.28). No período de 1906 a 1909 foi ainda substituto do professor Giacosa, na cátedra de anatomia da Real Academia Albertina de Belas-Artes (Didio, 1986, p.28).

A formação em anatomia que se solidificou no encontro da tradição italiana e germânica granjeou reputação a Bovero, que participou em 1909 da autópsia do cadáver de Cesare Lombroso (1835-1909)² e publicou uma série de estudos tanto na Itália quanto na Alemanha (Università..., s.d.). No contexto brasileiro, ele foi avaliado como um pesquisador e professor de "reconhecimento internacional", motivo que levou Arnaldo Vieira de Carvalho a convidálo a ocupar o cargo de lente de anatomia e fisiologia na Faculdade de Medicina e Cirurgia de São Paulo, criada em 1913 (Marinho, 2006, p.36). Não sem surpresa por parte dos médicos brasileiros, Bovero aceitou a proposta, sendo ainda nebulosos os motivos de sua disposição em abandonar a Europa em troca de um posto em um país com escassa tradição na pesquisa científica.

\section{A presença de Bovero em São Paulo}

\footnotetext{
Ser mestre é saber conservar-se jovem a despeito da idade; é desdobrar-se, multiplicar-se em seus discípulos criando escola, quando a maturidade intelectual se associa à força do sentimento. Deve ele falar ao espírito e dar o exemplo que toca à alma (Locchi, citado em Didio, 1986, p.53).
}

O convite de Arnaldo Vieira de Carvalho a Bovero foi parte de um projeto maior que pretendia levar para São Paulo médicos e cientistas europeus, sobretudo italianos, com o objetivo de impulsionar novas áreas de pesquisa (Salles, 1997, p.118-119). Ao mesmo tempo, a vinda de pesquisadores estrangeiros contribuiria para fazer da "Casa de Arnaldo" e do cenário acadêmico paulistano um local de produção de conhecimentos consoante com os propósitos da capital paulista de se modernizar, constituindo-se no lócus privilegiado de desenvolvimento 
científico-intelectual, econômico e social do país. Foi preciso, então, empreender esforços para a constituição de um corpus diferenciado que permitisse a construção de um saber médico que se queria "originalmente paulista", pelo menos em relação aos demais estados brasileiros (Motta, 2005, p.167).

Os primeiros anos de funcionamento da faculdade de medicina paulista foram pautados por uma série de dificuldades que abrangiam desde a escassez de verbas para a efetiva implantação de uma infraestrutura laboratorial consoante com o projeto inicial da faculdade até a dispersão das atividades, já que a escola dispunha, para suas atividades, de instalações dispersas e inadequadas. A superação desses óbices deveu-se ao apoio financeiro e institucional da Fundação Rockefeller, iniciado efetivamente em 1918 (Marinho, 2006, p.44). Foi sob a orientação dessa instituição que a escola foi organizada, havendo o interesse norte-americano de reproduzir na capital bandeirante os modernos postulados de ensino e pesquisa preconizados nos EUA e sintetizados, em 1910, no relatório elaborado sob a coordenação de Abraham Flexner (o qual se aproveitara de parte da tradição germânica que enfatizava o ensino articulado com a pesquisa) que, desde a sua elaboração tem sido alvo de críticas no referente à capacidade do modelo proposto de "atender às necessidades de saúde das sociedades onde foi implantado, isto é, em praticamente todo o mundo" (Pagliosa, Da Ros, 2008, p.493).

A presença do anatomista italiano foi aguardada com as expectativas depositadas em um europeu que iria trazer consigo novas ideias para a medicina nacional e, por isso, foi proposto a ele o distinguido papel de realizar a preleção inaugural do curso de medicina no ano de 1914. Apesar disso, devido a motivos pouco claros, os quais somavam problemas de ordem familiar e o cenário de pré-guerra na Europa, Bovero chegou a São Paulo somente no mês de abril, trazendo consigo um exemplar da primeira edição do De humani corporis fabrica de Vesálio, que atualmente está exposto no Museu de Anatomia Humana Professor Alfonso Bovero $^{3}$ (Didio, 1986).

Nessas circunstâncias, restou a Bovero dar prosseguimento às aulas de anatomia a partir de 25 de abril de 1914, numa disciplina que tinha sido iniciada um mês antes pelo professor substituto Sérgio Meira Filho. No ano seguinte, a faculdade ainda padecia da falta de especialistas e, nessa condição, o novo docente passou a reger também a cadeira de histologia (Montes, 2009, p.28; Lacaz, 1989, p.66).

A presença de Bovero em São Paulo, com a missão não só de lecionar sua especialidade, mas também de organizar o departamento de anatomia da jovem escola médica, inaugurou um novo período do ensino e da pesquisa em anatomia, o qual tem sido denominado "fase boveriana da anatomia brasileira". Dentre as contribuições do médico italiano é possível mencionar as obras clássicas e originais que trouxe consigo e a experiência nas técnicas de conservação a seco que aprendeu na Itália e na Alemanha, o que lhe permitiu impor um novo rigor no ensino e na pesquisa por ele engendrados (Liberti, 2010, p.8).

$\mathrm{O}$ fato de ser de imediato reconhecido como um intelectual proeminente permitiu ao recém-chegado ampliar seu círculo de atividades, especialmente no âmbito da colônia italiana de São Paulo, passando a contar com o apoio, também financeiro, do empresário Francisco Matarazzo. Primeiramente, estabeleceu sólidas relações com o nosocômio instituído pelos próprios italianos na cidade, o Hospital Umberto I, o que facilitou a criação de seus laboratórios e o desenvolvimento de pesquisas. Em 1923, Bovero também desempenhou papel de 
destaque na fundação da Associação Médica Ítalo-paulista, momento em que reiterou a importância da consolidação de uma associação de caráter "puramente científico" no âmbito paulista, antecedendo em sete anos a criação da Associação Paulista de Medicina (Salles, 1997, p.123-133).

No entanto, a tarefa de maior destaque de Bovero deu-se no campo do ensino e dos princípios que subjazem a esse processo. Na perspectiva boveriana da formação e prática anatômica, Liberti (2010, p.8) faz menção ao princípio da equidade, que, no ensino, mostravase sob duas perspectivas. A primeira delas refere-se à necessidade de "equanimidade entre o clássico e o contemporâneo", ou seja, ao equilíbrio entre o conhecimento básico, tradicional da disciplina, e os conhecimentos contemporâneos derivados das pesquisas recentes.

A formação acadêmica de Bovero, que aliou a docência e a pesquisa, foi uma síntese da proposta descritiva italiana com o experimentalismo, o comparativismo e o incentivo à pesquisa propostos pelos alemães, fazendo da combinação de ambas as tendências recurso necessário para a formação e a prática médicas. Com isso passava a ser rejeitado o modo de ensino de anatomia até então praticado no país, no qual o estudante tinha pouco acesso direto aos cadáveres e ralo incentivo para a pesquisa. No plano curricular, a anatomia deveria ter um lugar de destaque por constituir-se em uma disciplina do ciclo básico na formação médica. Decorrente dessa primeira linha passou-se a exigir dos estudantes um novo grau de desempenho e competência, além de um aumento considerável na carga horária destinada ao ensino de anatomia.

Na segunda perspectiva do princípio de equidade, Liberti (2010, p.9) referiu-se à realização de provas práticas de anatomia cujo conceito a ser obtido só poderia variar de "muito bom a excelente", conferindo assim novos e mais exigentes parâmetros avaliativos do conhecimento dos estudantes.

Os programas das disciplinas sob sua responsabilidade eram periodicamente atualizados e aperfeiçoados. No programa publicado em 1934 para os seis anos de duração do curso de medicina, Bovero ocupou a primeira cadeira de anatomia (parte descritiva), que deveria abranger osteologia, artrologia, miologia, angiologia, neurologia (sistema nervoso central e periférico) e estesiologia, de acordo com a seguinte metodologia:

A matéria será desenvolvida em aulas teórico-práticas diárias e em aulas práticas e demonstrações, em turmas ou em conjunto, como também com dissecções, cujo programa especificado será comunicado em tempo aos srs. alunos, levando-se em conta, naturalmente, o material já existente ou que chegar no laboratório. As aulas práticas abrangerão o estudo dos ossos, suas articulações e os diversos grupos musculares, principalmente no $1^{\circ}$ semestre. No $2^{\circ}$ semestre, além de completar o sistema muscular, deverão os alunos estudar o órgão central da circulação, as artérias, veias principais, os plexos nervosos e a parte dos órgãos viscerais que será desenvolvida no curso teórico-prático. Nas aulas teórico-práticas serão mais especialmente tratadas as questões gerais; nas aulas práticas a parte mais propriamente descritiva. O programa teórico-prático das diversas partes será resumido em pontos e estes consignados aos srs. alunos oportunamente, para os fins de exames semestrais ou finais. São Paulo, 30-XI-1934. O professor contratado. Dr. A. Bovero (Faculdade..., 1934, p.3-4).

Ainda no primeiro ano, paralelamente ao estudo da anatomia, os estudantes tinham que obrigatoriamente frequentar as aulas das disciplinas química fisiológica e parasitologia. 
O ensino de anatomia prosseguiria no segundo ano, com a previsão pelo programa, da disciplina anatomia topográfica, que passou a ser acompanhada pelo professor doutor Renato Locchi a partir de 1935. O curso antevia a anatomia topográfica do tronco e dos membros e deveria contemplar o aparelho urogenital, que não havia sido estudado durante o ano letivo de 1933, e os órgãos de secreção interna, o sistema nervoso central, órgãos da visão e da audição, sendo que estes últimos tópicos não haviam sido trabalhados em 1934 (Didio, 1986).

Constam sobre a metodologia da disciplina, distribuída em três aulas semanais, a dissecação e demonstração das regiões principais da cabeça, regiões do pescoço, regiões do tórax e abdômen, regiões dos membros superiores e inferiores, nervos cranianos, sistema nervoso simpático, órgãos da visão e audição. As aulas de anatomia no segundo ano ocorreriam concomitantemente com as disciplinas de histologia, embriologia e fisiologia. O programa do curso de anatomia topográfica foi elaborado e assinado por Bovero em 5 de dezembro de 1934 (Faculdade..., 1935).

Para o terceiro ano foi prevista a disciplina anatomia patológica - patologia geral e especial, que em 1936 foi ministrada pelo professor doutor Souza Aranha, concomitantemente às disciplinas parasitologia e microbiologia e imunologia. O programa desse curso foi proposto e assinado pelo professor L. da Cunha Motta, em 3 de dezembro de 1935 (Faculdade..., 1936).

Durante sua permanência no Brasil, Bovero desenvolveu com seus alunos um número significativo de pesquisas que foram publicadas nas revistas médicas nacionais e estrangeiras. Além disso, o carisma do mestre italiano e sua postura desafiadora frente aos alunos tornaramno diferenciado em certo grau dos demais docentes da faculdade, o que o faz ser lembrado até hoje por antigos médicos que foram seus pupilos. ${ }^{4}$

No início de 1937, já adoentado, ele partiu para a Itália para usufruir de um período de férias, vindo a falecer na cidade de Turim em 9 de abril daquele mesmo ano.

Nesse momento, apesar da limitação de informações sobre o assunto, já se preconizava a existência de uma escola boveriana em São Paulo, informação que se apresenta recorrente nos textos assinados por vários anatomistas que foram alunos de Bovero, oportunidades nas quais são reiteradas suas contribuições para o ensino e a pesquisa realizados no âmbito da Faculdade de Medicina de São Paulo.

Para os raros pesquisadores que se dedicaram ao tema da história da anatomia em São Paulo, uma das situações que conferiu um sentido mais evidente à existência da "escola" instituída por Bovero deu-se após a morte do professor italiano, mais precisamente no discurso proferido pelo professor doutor Renato Locchi quando assumiu a cátedra de anatomia descritiva e topográfica deixada por Bovero, em 19 de setembro de 1937 (Tavano, 2011, p.113; Didio, 1986, p.18). Parte do referido discurso do professor Locchi foi transcrita por Didio (1986, p.18):

A anatomia em São Paulo tem curta história, é moça como a própria faculdade, mas já se impôs e marcou época nos meios universitários brasileiros, e despertou a atenção de centros de estudos congêneres de outros países. É que, para nossa ventura máxima, foi organizada nos moldes das mais rigorosas escolas morfológicas europeias, pela mão forte de Alfonso Bovero, inteligência latina servida por disciplina germânica, de quem jamais se dirá todo o bem espiritual que nos trouxe e nos legou. Ao aportar em São Paulo, possuindo renome no meio internacional anatômico, por meio de intercâmbio científico bem orientado, torna conhecido e acatado em breve tempo, lá fora, o Departamento de 
Anatomia da Faculdade de Medicina de São Paulo, através dos trabalhos aqui realizados, seus, e, especialmente, de seus discípulos brasileiros.

No discurso pronunciado pelo acadêmico Helio Lourenço de Oliveira, nessa mesma ocasião, a existência da escola de Bovero foi reiterada, conforme a transcrição de Didio (1986, p.23): “o seu novo professor é a garantia segura e plena de que não se perderá um dos seus legítimos padrões de glória - a sólida Escola Anatômica fundada por Alfonso Bovero".

A partir dessa data, a escola anatômica paulista, ou boveriana, passou a ser cultuada no âmbito da Faculdade de Medicina da USP, sobretudo através das homenagens prestadas pelo professor Locchi a Bovero em suas aulas cotidianas e em datas específicas. Como relatou o professor Didio, quando havia aula de anatomia no dia 9 de abril, 5 a mesma era dedicada à vida e às obras de Bovero, e era denominada "comemoração do professor Bovero". Quando não podia ser realizada no dia 9, era transferida para o dia $25,{ }^{6}$ aniversário da aula inaugural do anatomista italiano em São Paulo. Depois da explanação inicial, o professor Locchi dividia os alunos em turmas e os levava para conhecer a saleta do "mestre", mantida intacta, como ele a havia deixado ao embarcar pela última vez para a Itália. Através desse ritual anual, o professor Locchi criou e manteve uma tradição que ajudou a difundir a escola boveriana no contexto paulista e nacional. O professor Didio relatou com eloquência a visita à saleta de Bovero:

Enquanto os grupos de oito alunos se sucediam o Prof. Locchi mostrava a cada grupo o pequeno escritório como um verdadeiro altar. A mesa, com tinteiro e outros pequenos objetos, todos bem dispostos, incluía até o vidro de cola que o próprio Prof. Bovero fazia por ser mais econômico, uma indicação da diligência com a qual administrava os dinheiros públicos. Nas paredes encontravam-se fotografias do Prof. Bovero, que aparecia em vários grupos de colegas e assistentes, e o quadro da formatura da turma de 1933, da qual fora paraninfo. Um armário continha livros e, ao lado, o enorme avental branco, correspondendo ao porte de um longitipo alpino, como era o Prof. Bovero, e uma longa vareta de bambu bege que, durante as projeções, lhe servia de apontador e, segundo as lendas dos estudantes, para acordar o servente quando este adormecia durante as aulas! O Prof. Locchi referiu que as únicas modificações que havia introduzido na saleta eram a colocação duma estatueta de bronze, representando o próprio Prof. Bovero, presenteada por uma turma de médicos após celebrar o aniversário de formatura, a troca da toalha de rosto, junto da pia, e a lavagem periódica do avental... Por fim, com o mesmo cuidado e carinho que se dispensa a uma criancinha, mostrou os cadernos do Prof. Bovero, que continha artigos copiados por ele a mão, com as figuras decalcadas meticulosamente das originais, a maioria representando giros ou circunvoluções cerebrais. Todos ficaram com a impressão de que haviam visto um verdadeiro tesouro e que o tesouro estava em boas mãos, bem protegido por um guarda a altura do seu extraordinário valor (Didio, 1986, p.29).

O relato de Didio mostra-se de valor para esse estudo, não só pela descrição do ritual de "comemoração de Bovero", mas também pelo significado que o próprio autor, enquanto membro da escola boveriana, confere ao registro desse relato na biografia do professor Locchi. E, assim, o autor prossegue:

Terminada a comemoração do Prof. Bovero houve intervalo mais longo do que o costumeiro, para que todos os grupos de estudantes pudessem ver as relíquias científicas, que a memorabília do professor Locchi mostrava. Com isso, os alunos tiveram tempo 
para se recuperar das emoções, voltar a respirar normalmente e reencetar as dissecações no laboratório de exercícios práticos. A inclusão de dados sobre a vida de Bovero na biografia do seu discípulo, ao resumir a exposição por este feita a seus alunos, foi intencional de nossa parte para seguir a orientação do professor Locchi, imaginando que teria sido esse o seu desejo e para mostrar a unidade da Escola Anatômica e a semelhança de seus altos desígnios, de suas carreiras e de suas atitudes como homens, como cientistas e como professores (Didio, 1986, p.29).

As primeiras tentativas de fortalecimento da escola anatômica de São Paulo foram empreendidas por Locchi, ao longo de sua trajetória acadêmica, o que pode ser bem exemplificado por sua posição frente à criação do Colégio Anatômico Brasileiro (CAB), fundado no Rio de Janeiro em julho 1942. No decorrer dos trabalhos de elaboração do primeiro estatuto do $\mathrm{CAB}$, previu-se como pré-requisito para seus membros que exercessem a medicina há pelo menos cinco anos e que tivessem residência estabelecida na região sede da associação (Tavano, 2011, p.146).

A criação do CAB foi imediatamente contestada pelos paulistas. Renato Locchi, então líder dos anatomistas de São Paulo e discípulo dileto de Bovero, negou-se a tomar parte do empreendimento. Para ele, a proposta estatutária do CAB, além de se mostrar regionalista, não levava em consideração as especificidades da ciência anatômica (Tavano, 2011, p.147). Segundo o próprio professor Locchi, em discurso proferido por ocasião da sua posse da cátedra de anatomia descritiva, em 19 de setembro de 1937, e transcrito por Didio (1986, p.24): "A anatomia estuda a forma e a estrutura, num estado estático-dinâmico (cadáver-vivente) da evolução do homem (em suas fases da vida)". O posicionamento dos paulistas colocava em evidência a própria questão da disciplina anatômica como um campo em construção que englobaria algumas ramificações da anatomia - anatomia humana, anatomia topográfica, anatomia descritiva, anatomia sistêmica, em detrimento de outras como a anatomia antropológica, fisiologia e anatomia patológica. Nessa ocasião também se tornaram explícitos os conflitos que existiam entre esses especialistas.

As relações nem sempre cordiais entre os anatomistas paulistas e os formados em outras escolas médicas do país coloca em tela uma questão crucial para o entendimento da história da anatomia e seu ensino: a constituição em São Paulo de uma linhagem de anatomistas que, inaugurada com a atuação no Brasil do italiano Alfonso Bovero, buscava contrapor-se, pelo menos parcialmente, àquela preconizada no Rio de Janeiro e em Salvador. Devido a isso, Tavano (2011, p.111) concluiu que a "Escola de Bovero é nome dado por Renato Locchi ao grupo de profissionais que trabalharam e produziram com ele, ou sob sua orientação, mas extrapola a personificação nos discípulos e o espaço-tempo de permanência do mestre e solidifica-se como o método e o rigor científico que instaurou em São Paulo".

\section{A primeira geração boveriana}

Em 1934, com a criação da Universidade de São Paulo (USP), os discípulos de Bovero foram submetidos ao regimento da instituição, encontrando-se em condições de ocupar posições de destaque nos diversos departamentos dos cursos de ciências biológicas e biomédicas e, em seguida, aplicar os princípios da "escola" a qual pertenciam em outras instituições de 
ensino superior que foram surgindo na capital, no interior do estado e em outras unidades da federação. Com isso, consagrou-se não só a institucionalização do ensino de anatomia nos novos cursos que estavam sendo estruturados como também se buscou manter o espírito boveriano como orientador do ensino e das pesquisas realizadas na área.

Segundo Liberti (2010, p.5), com exceção dos professores catedráticos, ingressava-se na carreira de anatomia, pelo menos no regime da USP, como preparador, assistente ou auxiliar de ensino. Para ser contratado como professor assistente II, o que se dava através de concurso, o candidato deveria comprovar um mínimo de três anos como assistente voluntário ou colaborador de algum curso, atividade que hoje pode ser comparada com os trabalhos de monitoria. Além disso, também teria que ter obrigatoriamente cursado a disciplina "técnicas anatômicas".

Da primeira geração de discípulos de Bovero destacou-se um grupo que ocupou posições importantes não só na USP, mas também em outras instituições de ensino e pesquisa. Além de Renato Locchi (1896-1978) que, com a morte de Bovero, sucedeu-o na cátedra de anatomia descritiva e topográfica da Faculdade de Medicina, destacam-se ainda na década de 1930, no contexto paulista, João Moreira da Rocha, que se tornou catedrático de anatomia na Escola Paulista de Medicina e também no curso de odontologia da USP, e Max de Barros Erhart, catedrático na Faculdade de Medicina Veterinária e Zootecnia da USP. Ainda da mesma geração, ganharam destaque Odorico Machado de Souza, que assumiu a cátedra de Locchi, quando este se aposentou em 1956, e Olavo Marcondes Calasans, que, juntamente com Machado de Souza, responsabilizou-se em 1951 pela organização do Departamento de Anatomia da Faculdade de Medicina de Sorocaba, mais tarde integrada à Pontifícia Universidade Católica de São Paulo (Liberti, 2010, p.5).

Desses, certamente foi Renato Locchi o nome de maior relevo e o principal continuador da obra de Bovero. Os empreendimentos realizados por Locchi ao longo de sua trajetória acadêmica e, sobretudo, a sua inserção em comissões e congregações, tanto no âmbito da USP quanto fora dela, garantiram à anatomia as condições necessárias para que as várias disciplinas incorporadas pela área firmassem sua identidade e importância no ensino superior paulista sob a chancela da "escola boveriana de anatomia". Tal consolidação conta como principal indício a intensa carga horária concedida à anatomia na grade curricular do curso de medicina da USP, sendo que uma parte substancial da documentação referente aos esforços institucionais, ensino e pesquisa realizada por esse anatomista foram estudados por Tavano (2011).

Ainda é Tavano (2011) quem oferece elementos que permitem acompanhar os trabalhos desenvolvidos na cátedra por Locchi, que ocupou essa posição na Faculdade de Medicina da USP de 1937 a 1955 lecionando a disciplina "anatomia humana". Ao longo desse período, a disciplina, como já propunha Bovero, foi sendo continuamente reformulada em busca de atualização conteudística e aprimoramento didático-pedagógico, possibilitando que algumas características metodológicas do ensino de anatomia se mostrassem relevantes.

Em primeiro lugar, manteve-se a tradição da prática da dissecação como parte crucial do processo de ensino e aprendizagem, reproduzindo, no contexto da formação inicial dos estudantes, uma prática secular que fundamentou as pesquisas na área. Além da dissecação de peças anatômicas, também cabia ao aluno sua apresentação e arguição, que eram tarefas 
importantes no processo formativo e avaliativo que, conforme havia estipulado Bovero, privilegiava a parte descritiva da disciplina no currículo.

Essa proposta articulava-se com as necessidades e expectativas de um curso de medicina e mostrava-se inovadora no contexto da dissecação sistemática ao longo da disciplina. Incorporava aspectos tradicionais da prática anatômica, como a observação das estruturas macroscópicas e a dissecação, aliando-as a uma postura de dúvida metódica e levantamento bibliográfico. Assim, tentava-se também estabelecer um campo de saber disciplinar que ultrapassava a grade curricular, tanto da Faculdade de Medicina, como de outras unidades da USP, num empenho grupal de instituir uma área de pesquisa que desfrutasse de uma boa dose de autonomia (Liberti, 2010, p.6; Tavano, 2011, p.172).

$\mathrm{O}$ ensino aliado à pesquisa foi, portanto, marca da escola boveriana de anatomia. Nesse cenário, apesar da autoridade exercida pelo professor catedrático, o aluno desfrutava de liberdade para construir seu próprio conhecimento. Para tanto, o catedrático tinha à sua disposição farto material anatômico e contava com o apoio de assistentes bem preparados para respaldar a parte prática da disciplina a qual, aliás, tomava grande parte da carga horária em detrimento do tempo investido no ensino teórico, que deveria ser buscado nos livros e artigos de revistas especializadas pelos próprios estudantes (Didio, 1986, p.19).

A dissecação e a observação empírica de peças anatômicas foram práticas comuns sobre as quais se pautou o ensino de Bovero e seus sucessores. A partir de meados da década de 1940, uma série de contingências relativas à formação médica e ao desenvolvimento de pesquisas em subáreas da anatomia impôs que a parcela descritiva do curso fosse cedendo lugar e tempo a outras "subculturas" anatômicas, como a anatomia topográfica e a neuroanatomia. Devido a isso, conteúdos próprios do ensino de anatomia, especialmente no referente à parte descritiva, foram alocados em disciplinas do âmbito da clínica e da cirurgia (Tavano, 2011, p.178).

Esse movimento fez com que as práticas de ensino empreendidas fossem reformuladas ao longo dos anos a partir dos objetivos e demandas de cada uma das múltiplas facetas das "novas anatomias" incluídas no currículo de formação médica. A disciplina que se consagrara como básica na década de 1930, concentrando para si todo o conteúdo descritivo e topográfico da anatomia humana, a partir de 1950, passou a subsidiar novos saberes, dos quais se destacou a parte funcional.

Na conferência intitulada "A pesquisa em anatomia", proferida pelo professor Locchi em janeiro de 1953, na Faculdade de Ciências Médicas de Minas Gerais, o problema da pesquisa em anatomia foi desdobrado a partir de uma divisão do próprio conteúdo: primeiro em anatomia macro e microscópica e, depois, em "anatomia" como um conceito mais amplo:

A primeira foi a princípio uma arte de dissecar, que se tornou ciência pela soma de conhecimentos que proporcionou. Dissecaram-se cadáveres, humanos e de animais, estes também em períodos gravídicos, surgindo os primeiros ramos da anatomia: ao lado da anatomia humana, a comparativa e a incipiente embriologia. Sempre, porém, o estudo fundamental da forma, que é a linguagem pela qual nos fala o corpo humano. Os meios técnicos permitiram mais tarde o exame com lentes, e cria-se a histologia, e aprofunda-se a análise do mundo microscópico da forma, sentiu-se logo a necessidade premente de, diante da massa imensa de dados acumulados e da grande variedade de forma e fatos (quer se considere um ser ou em sua parte), de uma ordenação da matéria. Reúnem-se órgãos, estruturas, elementos, segundo suas conexões percebidas 
ou supostas; formam-se os sistemas orgânicos, grupos de órgãos como instrumentos de função. Aparece mais nítida a preocupação do valor funcional dentro da forma, mais nítida e científica, porque evidentemente desde as primeiras observações ocasionais dos homens primitivos, a instintiva curiosidade nascente e crescente fez interrogar o valor daquele órgão ou partes, desmembrados na primeira presa abatida ou no corpo do inimigo vencido e esquartejado (citado em Didio, 1986, p.68).

A implantação do ensino de anatomia com carga horária ampliada não só na Faculdade de Medicina, mas também em outros cursos da USP, resultou em uma série de dificuldades no ensino, como a escassez de material anatômico para suprir a demanda sempre crescente. Apesar disso, Locchi e os demais anatomistas da USP empenharam-se em manter viva a tradição boveriana. O uso de peças anatômicas para demonstrações, a disponibilização de peças preparadas para observação, estudo e fixação das estruturas por parte dos alunos conjugava-se com o propalado rigor da "disciplina", entendido como o labor e o tempo despendidos pelos estudantes na aprendizagem dos conteúdos anatômicos. Além disso, utilizavam-se também livros textos e atlas anatômicos como estratégias auxiliares para que os alunos identificassem as estruturas estudadas.

O empenho dos anatomistas formados no âmbito paulista constituía-se não só em um empreendimento de ensino e pesquisa como também em uma ação político-institucional, no sentido que se buscava consagrar a anatomia como um campo científico segundo os interesses e perspectivas do grupo boveriano, portanto independente do CAB.

No final de 1951, Locchi conseguiu verba para patrocinar a vinda ao Brasil do professor Angelo Cesare Bruni, um dos discípulos europeus mais velhos de Bovero e diretor do Instituto de Anatomia Humana Normal da Università degli Studi, de Milão. Segundo Didio (1986, p.60), o professor Bruni fez uma notável conferência intitulada "Bovero, l'Uomo", analisando a personalidade do "mestre" desde o primeiro encontro até a morte. $\mathrm{O}$ anfiteatro de anatomia estava tomado por um público significativo, e a palestra se constituiu numa "autêntica apoteose".

No final de julho de 1952, o Departamento de Anatomia Descritiva e Topográfica da Faculdade de Medicina da USP patrocinou a Primeira Reunião Brasileira de Anatomia, sob a presidência de Álvaro Froés da Fonseca. Para apoiar essa iniciativa de Locchi, vários deputados haviam apresentado, no ano anterior, projetos de lei junto à Assembleia Legislativa do estado de São Paulo, através dos quais solicitavam verbas para o evento. No dia 7 de agosto de 1951, a assembleia aprovou o projeto de lei 814, que concedeu Cr\$120.000,00 (cento e vinte mil cruzeiros) à Primeira Reunião Brasileira de Anatomia e Antropologia (Didio, 1986, p.62) . Esse evento foi de importância vital não somente para o estabelecimento de autonomia à disciplina anatômica, como foi também uma reiteração do investimento político e econômico destinado à anatomia em São Paulo.

No dia 31de julho de 1952, durante a sessão de encerramento do evento, Renato Locchi pediu a palavra e propôs a fundação da Sociedade Brasileira de Anatomia (SBA), "congregando todos os cultores da Morfologia Normal do Brasil". De imediato foi apresentado e discutido o anteprojeto de estatuto social da nova associação, com 14 artigos os quais, após votação do plenário, foram aprovados. Por proposta do presidente da reunião, Locchi foi aclamado por unanimidade instituição primeiro presidente da instituição (SBA, s.d.). 
A primeira geração dos anatomistas boverianos cumpriu sua missão, a qual já se mostrava implícita na proposta do próprio fundador da escola. A primeira reunião da SBA foi realizada em Curitiba em julho de 1954; a partir da quinta edição do evento, ocorrida em 1967, o certame passou a denominar-se Congresso Brasileiro de Anatomia, certamente para reforçar ainda mais sua abrangência nacional.

\section{A segunda geração boveriana}

Da segunda geração de anatomistas da escola boveriana destacaram-se o professor Liberato J.A. Didio, docente da faculdade de medicina da Universidade Federal de Minas Gerais, que foi discípulo de Locchi, e também Plínio Pinto da Silva, por sua vez discípulo de Max de Barros Erhart, que em 1954 se tornou catedrático de anatomia na Faculdade de Medicina Veterinária da USP. Pinto e Silva aposentou-se em 1962, assumindo, a partir de então, posto semelhante na Faculdade de Ciências Médicas e Biológicas de Botucatu, hoje incorporada à Universidade Estadual Paulista, sendo que seus alunos atualmente ocupam cargos docentes na área de anatomia em várias instituições de ensino e pesquisa de São Paulo e de outros estados, não sendo raro que em palestras e em salas de aula esses especialistas se apresentem até hoje como membros da escola boveriana de anatomia (Apamvet, 2011).

Em 1968, com a lei 5.540/68, que instituiu a reforma universitária, as cátedras foram abolidas das universidades. A semestralidade das disciplinas, a criação de ciclos básicos de ensino, a implantação do sistema de créditos para a composição da grade curricular, entre outras medidas, fizeram com que o ICB da USP fosse criado naquele mesmo ano.

No plano organizacional das instituições, portanto, houve, no final da década de 1960, um realocamento dos docentes das disciplinas pré-clínicas, como as anatomias, farmacologias, fisiologias etc., dos departamentos aos quais pertenciam dentro das faculdades de Odontologia, Farmácia e Medicina para o ICB (Início..., 2011). Inicialmente, o ICB foi composto pelos departamentos de Anatomia, Histologia, Fisiologia, Microbiologia e Parasitologia.

A partir de sua constituição o ICB passou a ministrar disciplinas de graduação de anatomia, farmacologia, fisiologia, histologia e embriologia, imunologia, microbiologia e parasitologia a alunos de vários cursos da área da saúde. Inicialmente os alunos eram os matriculados nas faculdades das áreas de saúde, tais como Faculdade de Medicina Veterinária, Faculdade de Odontologia, Faculdade de Medicina, Faculdade de Ciências Farmacêuticas, Instituto de Biociências, assim como a alunos dos cursos de Fisioterapia, Nutrição, Enfermagem, Fonoaudiologia, Terapia Ocupacional, ligados às Faculdades de Medicina e de Saúde Pública. Com o tempo o leque de alunos do ICB se ampliou abrangendo alunos de Educação Física e Esportes, Psicologia, Engenharia Civil - Modalidade Ambiental, Química e Ciências Moleculares (Histórico..., 2011).

Segundo Liberti (2010, p.6), a fusão dos corpos docentes de anatomia das faculdades de Medicina e Odontologia fez do novo Departamento de Anatomia do ICB, um "prestador de serviços didáticos", atuando em uma vasta gama de cursos que paulatinamente foram sendo implantados na USP, como fisioterapia, educação física, fonoaudiologia, nutrição, psicologia, entre outros. Em março de 2011, o Departamento de Anatomia do ICB contava com 19 
docentes responsáveis por ministrar 28 disciplinas de graduação e 12 cursos profissionalizantes, atendendo aproximadamente 1.200 alunos. Além disso, também contava com um Programa de Pós-graduação em Ciências Morfofuncionais (Graduação, s.d.).

No âmbito da Coordenação de Aperfeiçoamento de Pessoal do Nível Superior (Capes), as disciplinas anatomia, anatomia humana e anatomia animal (exceto anatomia patológica e anatomia patológica animal) são registradas como áreas básicas, ou especialidades da subárea morfologia, que, junto com a fisiologia, compõe a grande área Ciências Biológicas II.

Em março de 2011, segundo o site da Capes, existiam 68 programas de pós-graduação (PPG) na grande área Ciências Biológicas II, ${ }^{7}$ dos quais oito eram em morfologia (mestrado e doutorado). Desses oito programas, apenas um tinha por área básica a anatomia: o Programa de Pós-graduação em Ciências Morfofuncionais, vinculado ao ICB/USP. A anatomia também foi mencionada como área de concentração em um segundo programa, o PPG em Ciências Morfológicas, da Universidade Federal do Rio de Janeiro (UFRJ), cuja área básica era morfologia (Brasil, 2010).

Esses dados apontaram para um declínio na formação de pesquisadores em anatomia humana/animal em comparação ao número de programas, e, portanto, da demanda de investigação científica apresentada por outras subáreas como a bioquímica (19 programas), farmacologia (16 programas) e fisiologia (21 programas), reconhecidos pela Capes, só estando à frente dos programas em biofísica (quatro). A grande questão lançada pela geração atual de anatomistas brasileiros (que muito comumente se autodenominam "anatomossauros") "qual o futuro da anatomia no Brasil e no mundo?" - está em suspenso. Urge, portanto, repensar a formação do anatomista e, mais especificamente, do professor de anatomia, que deverá, a despeito dos avanços nas pesquisas científicas, para as quais a anatomia não passa de uma especialidade, continuar a exercer seu papel fundamental de educador acadêmico.

Essas observações foram corroboradas em várias momentos, especialmente no transcorrer do 24ํ Congresso de Anatomia, realizado em Ribeirão Preto em outubro de 2010. No decorrer das palestras e em conversas informais, detectou-se a percepção, tanto de "velhos" quanto de jovens anatomistas, que em conjunto não deixaram de louvar a memória de Bovero e dizer-se filiados à "escola" aqui focada, de que tanto a pesquisa quanto o ensino de anatomia encontram-se em um momento de crise. No âmbito da pesquisa porque, apesar das novas tecnologias aplicadas às pesquisas, afirmou um deles, "pouco de novo pode ser trazido para a área", acrescentando que, embora atue como docente titular da disciplina em uma das principais escolas médicas do país viu-se diante da contingência de deslocar o eixo de suas pesquisas para outras áreas da medicina, as quais - ressaltou - são mais valorizadas por seus colegas acadêmicos e pela sociedade.

Quanto ao ensino, observa-se que o professor de anatomia encontra-se em um impasse: reproduzir o ensino "magistral" baseado na exposição de peças anatômicas e na memorização, ou buscar uma renovação de suas práticas pedagógicas sem, com isso, abandonar sua identidade profissional como membro da escola boveriana de anatomia.

Outro anatomista, também professor de uma reputada escola médica, disse que não via mais sentido em lecionar a disciplina como um saber relativamente autônomo, sendo que fazia anos que adotara a estratégia de ensino de ministrar as aulas acompanhado por docentes de disciplinas afeitas à sua, como a fisiologia, o que permitia que a anatomia "fizesse sentido 
na cabeça dos alunos" e não fosse apenas um saber cujo conteúdo estava fadado a ser "apenas memorizado". Montes e Souza (2010, p.5) observam que, entre os desafios pertinentes à necessária renovação do ensino de anatomia, figura um maior entendimento dos processos cognitivos envolvidos na aprendizagem desses conteúdos específicos por parte dos alunos que, além de memorizar a nomenclatura anatômica, devem ser capazes de compreender as relações entre "nome-posição-forma-função".

\section{Considerações finais}

Tendo percorrido um pouco da trajetória da anatomia no Brasil, procurou-se elencar alguns dos aspectos históricos, sociais e culturais que permitiram a consagração da disciplina anatômica como campo de saber estruturado nos moldes estabelecidos pela ciência moderna. No âmbito brasileiro, e mais especificamente paulista, foi criada e mantida uma escola anatômica pretensamente tradicional, pautada por rituais e homenagens ao seu fundador, o anatomista italiano Alfonso Bovero.

A proposta de ensino e pesquisa inaugurada por Bovero mostrou-se inovadora no contexto brasileiro. No entanto, um olhar mais minucioso acerca de suas propostas e prerrogativas insinua que o seu modelo de ensino/pesquisa fora semelhante ao empreendido por Mondino, no século XIV, e Vesalius, no século XVI, considerados os "reformadores" da anatomia e que, ao dar prioridade à prática da dissecação e ao uso de compêndios e livros textos, instauraram um método tradicional de ensino e pesquisa que caracteriza a disciplina anatômica.

Nessas circunstâncias, apesar da continuidade de afirmações sobre a existência de uma escola boveriana de anatomia, busca-se aqui relativizar sua existência. Isso porque Alfonso Bovero limitou-se a reproduzir no contexto paulista o compromisso de pesquisa e estratégias de ensino que ele próprio havia aprendido na Europa, especialmente durante o estágio que realizou na Alemanha. Por outro lado, o ímpeto dos discípulos de Bovero em erigir uma tradição em homenagem ao mestre italiano ensejou uma multiplicidade de discursos - iniciada ainda no final da vida de Bovero e que se mantém viva até hoje, mesmo que pautada por nuanças. Assim, fala-se na existência da "escola" mais em termos simbólicos, como estratégia de congregação de um grande número de anatomistas, do que em um modelo inovador que aqui tenha sido implantado em concomitância com o surgimento da Faculdade de Medicina de São Paulo.

\section{NOTAS}

${ }^{1}$ Quain's elements of anatomy. Compilação em três volumes de livro-texto, das contribuições anatômicas de John Quain (1796-1865), Richard Quain (1800-1887) e Sir John Richard Quain (1816-1876).

${ }^{2}$ Médico, cirurgião e criminalista italiano, ficou conhecido por seus estudos em antropologia criminal.

${ }^{3}$ Mantido pelo Instituto de Ciências Biológicas (ICB) da Universidade de São Paulo.

${ }^{4}$ Veja-se o depoimento do professor de parasitologia e antigo aluno de Bovero na Faculdade de Medicina da USP. Disponível em: http://www.youtube.com/watch?v=wSSqSgsXQFM. Acesso em: 5 abr. 2013.

${ }^{5}$ Aniversário de morte do professor Bovero.

${ }^{6}$ Todo dia 25 de abril, era praxe os alunos deixarem um buquê de flores no pedestal do busto do professor Bovero, no saguão do Departamento de Anatomia do ICB/USP.

${ }^{7}$ No total de 265 programas de pós-graduação em ciências biológicas. 


\section{REFERÊNCIAS}

ABREU, Jean Luiz N.

Os estudos anatômicos e cirúrgicos na medicina portuguesa do século XVIII. Revista da SBHC, v.5, n.2, p.149-158. 2007.

AIRES NETO, José.

O ensino de anatomia no Brasil. Revista Brasileira de Estudos Pedagógicos, v.12, n.33, p.78-94. 1948.

ARAUJO, Carlos da Silva.

Fatos e personagens da história da medicina e da farmácia no Brasil. Revista Continente, v.1, p.32. 1979.

\section{APAMVET.}

Associação Paulista de Medicina Veterinária. A vida dos patronos e acadêmicos da Academia Paulista de Medicina Veterinária. Disponível em: http://www.apamvet.com/apamvet05d.html. Acesso em: 29 mar. 2011. 2011.

BRASIL.

Ministério da Educação e Cultura. Capes Coordenação de Aperfeiçoamento de Pessoal do Nível Superior. Relação de cursos recomendados e reconhecidos. Ciências Biológicas. Disponível em: www.conteudoweb.capes.gov.br/conteudoweb/ ProjetoRelacaoCursosServlet?acao=pesquisarAre a\&codigoGrandeArea $=20000006 \&$ descricaoGra ndeArea $=$ CI $\%$ C3 $\% 26 \% 23138 \% 3 B N C I A S+B I O L \%$ C3\%26\%23147\%3BGICAS+. Acesso em: 30 mar. 2011. 2010.

COLEMAN, William.

Biology in the Nineteenth Century: problemas of form, function, and transformation. Cambridge: Cambridge University Press. 1977.

DIDIO, Liberato J.A.

Biografia do professor Renato Locchi: um gigante das ciências anatômicas. Rio de Janeiro: Guanabara Koogan. 1986.

ERHART, Eros A.

Elementos de anatomia humana. São Paulo: Atheneu. 1973.

FACULDADE...

Faculdade de Medicina da Universidade de São Paulo. Programas do $3^{\circ}$ ano para 1936. São Paulo: Revista dos Tribunais. p.1-33. 1936.

FACULDADE...

Faculdade de Medicina da Universidade de São Paulo. Programas do $2^{\circ}$ ano para 1935. São Paulo: Imprensa Oficial do Estado. p.1-27.1935.

FACULDADE...

Faculdade de Medicina da Universidade de São Paulo. Programas do $1^{\circ}$ ano. São Paulo: Imprensa Oficial do Estado. p.1-15. 1934.
GRADUAÇÃO.

Graduação. Instituto de Ciências Biomédicas da Universidade de São Paulo. Disponível em: http://www.icb.usp.br/ anatomia/graduacao. html. Acesso em: 30 mar. 2011. s.d.

HAYES, Bill

The anatomist: a true history of Gray's Anatomy. New York: Random House. 2008.

HISTÓRICO...

Histórico do Instituto de Ciências Biomédicas.

Disponível em: http://www3.icb.usp.br/ corpoeditorial/index.php?option=com_content\& view=article\&id=163\&Itemid=174. Acesso em: 29 mar. 2011. s.d.

INÍCIO...

Início do Instituto de Ciências Biomédicas da Universidade de São Paulo. Disponível em: http://www3.icb.usp.br/corpoeditorial/index. php?option=com_content $\&$ view=article $\& i d=163$ \&Itemid=174. Acesso em: 30 mar. 2011. s.d.

KRUSE, Maria Henriqueta L.

Anatomia: a ordem do corpo. Revista Brasileira de Enfermagem, v.57, n.1, p.79-84. 2004.

LACAZ, Carlos da Silva.

Médicos italianos em São Paulo: trajetória em busca de uma nova pátria. São Paulo: Aquarela. 1989.

LACAZ, Carlos da Silva.

Ensaios médico-sociais. São Paulo: Fundo Byk. 1986.

LAÍN ENTRALGO, Pedro.

Historia universal de la medicina. Cd-rom. Buenos Aires: Masson Multimedia. 1999.

LALANDE, André.

Vocabulário técnico e crítico da filosofia. São Paulo: Martins Fontes. 1999.

LE BRETON, David.

La chair à vif: usages medicaux et moundains du corps humain. Paris: A.M. Métalié. 1993.

LIBERTI, Edson.

A escola anatômica de Bovero: de onde veio, para onde vai? O anatomista, ano 1, v.1, p.4-10. Disponível em: http://www.sbanatomia.org. br/arquivos/v1n1.pdf. Acesso em: 21 set. 2010. 2010.

MANDRESSI, Rafael.

Le regard de l'anatomiste. Paris: Seuil. 2003.

MARINHO, Maria Gabriela S.M.C.

Trajetória da Faculdade de Medicina da Universidade de São Paulo: aspectos históricos da "Casa de Arnaldo". São Paulo: FMUSP. 2006. 
MONTES, Marco Aurélio de Azambuja. Reflexões sobre o ensino de anatomia humana: subsídios para pensar sobre propostas de ensinoaprendizagem. Tese (Doutorado) - Instituto Oswaldo Cruz, Rio de Janeiro. 2009.

MONTES, Marco Aurélio de Azambuja; SOUZA, Claudia Teresa Vieira de.

Estratégias de ensino-aprendizagem de anatomia humana para acadêmicos de medicina. Ciências $e$ Cognição, v.15, n.3, p.2-12. 2010.

MOTTA, André.

A casa de Arnaldo. In: Motta, André. Tropeços da medicina bandeirante: medicina paulista entre 1892-1920. São Paulo: Edusp. p.167-220. 2005.

PAGLIOSA, Fernando Luiz; DA ROS, Marco Aurélio.

O relatório Flexner: para o bem e para o mal. Revista Brasileira de Educação Médica, v.32, n.4, p.492-499. 2008.

SALLES, Maria do Rosário Rolfsen.

O caráter da inserção profissional em São Paulo. In: Salles, Maria do Rosário Rolfsen. Médicos italianos em São Paulo (1890-1930): um projeto de ascensão social. São Paulo: Sumaré/Fapesp. p.93148. 1997.

SANTOS FILHO, Lycurgo.

História geral da medicina brasileira. São Paulo: Hucitec. v.2. 1991.

SANTOS FILHO, Lycurgo.

História geral da medicina brasileira. São Paulo: Hucitec. v.1. 1977.

SINGER, Charles.

Uma breve história da anatomia e fisiologia desde os gregos até Harvey. Campinas: Editora da Unicamp. 1996.
SBA.

Sociedade Brasileira de Anatomia. A história da SBA. Disponível em: http://www.sbanatomia.org. br/historico.php. Acesso em: 30 mar. 2011. s.d.

TAVANO, Patrícia Teixeira.

Onde a morte se compraz em auxiliar a vida: a trajetória da disciplina de anatomia humana no currículo médico da primeira faculdade oficial de medicina de São Paulo: período de Renato Locchi (1937-1955). Dissertação (Mestrado) - Faculdade de Educação, Universidade de São Paulo, São Paulo. 2011.

TERRA, Vinicius de Marchi.

Memórias anatômicas. Tese (Doutorado) Faculdade de Educação, Universidade Estadual de Campinas, Campinas. 2007.

TORRES HOMEM, João Vicente.

Elementos de clínica médica: seguidos do anuário das mais notáveis observações colhidas nas enfermarias de clínica médica em 1869. Rio de Janeiro: Nicolão A. Alves. 1870.

TORRES HOMEM, João Vicente.

Utilidade das cadeiras criadas em 1854 nas faculdades de medicina. Gazeta Medica do Rio de Janeiro, n.5, v.10, p.51-52. 1862.

UNIVERSITÀ...

Università Degli Studi di Palermo.

Catalogo inventario. Accademia scienze mediche. Disponível em: www.unipa.it/.../atti/ Inventario\%20Accademia\%20completo.doc. Acesso em: 23 maio 2011. s.d. 